\title{
Quantification of Ethanol Content in Traditional Herbal Cough Syrups
}

\author{
Ming Shin Neo', Shraddha Manish Gupta ${ }^{1,2}$, Tahir Mehmood Khan', Manish Gupta ${ }^{1 *}$
}

\section{Ming Shin Neo', Shraddha Manish Gupta ${ }^{1,2}$, Tahir Mehmood Khan', Manish Gupta ${ }^{1 *}$ \\ 'School of Pharmacy, Monash University \\ Malaysia, Selangor, MALAYSIA. \\ ${ }^{2}$ Gurukrupa Institute of Pharmacy, $\mathrm{NH}$ \\ 222, Near Chhatrapati Sugar Factory, \\ Malipargaon Phata, Majalgoan, \\ Beed 431131, Maharashtra, INDIA. \\ Correspondence \\ Manish Gupta}

School of Pharmacy, Building 2, Level 5, Room 2-5-53, MONASH University MALAYSIA

Jalan Lagoon Selatan, 47500 Bandar Sunway, Selangor Darul Ehsan, MALAYSIA.

Phone no: + 60355145685

E-mail: manish.gupta@monash.edu

\section{History}

- Submission Date: 29-06-2017;

- Review completed: 01-07-2017;

- Accepted Date: 27-08-2017.

DOI : 10.5530/pj.2017.6.128

Article Available online http://www.phcogj.com/v9/i6

\section{Copyright}

(C) 2017 Phcog.Net. This is an openaccess article distributed under the terms of the Creative Commons Attribution 4.0 International license.

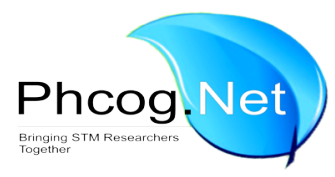

\begin{abstract}
Introduction: The use of alcohol as an excipient in pharmaceutical preparations raises safety concerns, especially when used in high concentration. This study aims to scrutinize the ethanol concentration in traditional herbal cough syrups available over-the-counter (OTC) in Malaysia. Method: Enzymatic analysis was adopted to estimate the alcohol contents of five selected syrups. The principle reaction involved ethanol oxidation by nicotinamide-adenine dinucleotide (NAD) in the presence of the enzyme alcohol dehydrogenase $(\mathrm{ADH})$, forming acetaldehyde, reduced NAD (NADH) and a proton. The ethanol concentration of each syrup was quantitatively determined by detecting NADH using UV spectrophotometry at detection wavelength of $340 \mathrm{~nm}$. Results: The ethanol percentage by volume (\% v/v) in the tested syrups ranges from $0.102 \%$ to $2.576 \%$. All five syrups studied comply with the FDA requirement for drugs for adults and children $>6$ years since they do not contain more than $5 \%$ ethanol. However, three syrups do not fulfil the requirement for use in children $<6$ years as they contain higher than $0.5 \%$ ethanol, yet they are inappropriately indicated on their packaging for use in children $>3$ years. In terms of safety, all studied syrups fulfil European Medicine Agency's (EMA) recommendation as they will not induce a blood alcohol concentration (BAC) higher than $0.125 \mathrm{~g} / \mathrm{L}$ after a single dose. Nevertheless, none of these syrups comply with Malaysian Drug Registration Guidance on labelling requirements as they do not disclose their alcohol contents on the packaging. Conclusion: More rigorous regulation on alcohol content in herbal preparations, and disclosure of alcohol content in product packagings should be enforced. Key words: Alcohol content, Enzymatic analysis, Ethanol concentration, Herbal cough medicine, Herbal preparation, Quantitative analysis.
\end{abstract}

\section{INTRODUCTION}

Background

Ethanol is an extensively used excipient in various pharmaceutical formulations. ${ }^{1}$ It can function as a cosolvent to increase drug solubility, and as a preservative due to its antimicrobial activity. ${ }^{1,2}$ In herbal medicines, ethanol is often used as an extraction solvent to obtain the constituents of the herbs necessary for the product efficacy. ${ }^{2,3}$ Notably, many herbal liquid formulations use ethanol as part of their active substances instead of as excipient. ${ }^{3}$ Ethanol contents in pharmaceutical products vary in different formulations; higher ethanol concentrations are most commonly used in liquid formulations such as syrups, solutions and suspensions. According to a review article by Strickley R., the maximum amount of ethanol reported in oral solution and elixir formulations is $42 \%{ }^{4}$ The American Academy of Paediatrics reported that the alcohol content of liquid preparations intended for children ranges from 0.3 to $68 \% \mathrm{v} / \mathrm{v}^{5}$ Fiocchi et al. reported that up to $60 \% \mathrm{v} / \mathrm{v}$ ethanol can be found in over-the-counter (OTC) and homeopathic products. ${ }^{6}$ There are growing concerns for the presence of ethanol in pharmaceutical and herbal preparations due to the safety, religious and social con- cerns associated with alcohol intake. Hence, the use of ethanol as an excipient and its maximum allowed concentration need to be regulated. Also, ethanol content should be disclosed on packaging to allow consumers to make informed judgement when purchasing medicinal products. However, many traditional herbal preparations that are available without a prescription do not disclose the alcohol concentrations present in their preparations.

\section{Safety concerns associated with ethanol use}

Safety is the primary issue arising from the use of ethanol in medicinal products, especially when it is used in high concentrations. The harmful effects of ethanol exposure are due to its central nervous system (CNS) depressant nature. ${ }^{1,2}$ Martindale defines blood alcohol concentrations (BACs) of up to 180 $\mathrm{mg} / 100 \mathrm{~mL}$ as low concentrations, which may cause visual impairment, slower reaction time, coordination impairment and emotional lability. ${ }^{1}$ Low to moderate BACs, defined as 180 to $350 \mathrm{mg} / 100 \mathrm{~mL}$, may result in cortical function depression, causing 
slurred speech, diplopia, blurred vision, ataxia, loss of judgment, blackouts, sweating, tachycardia, nausea, vomiting, and incontinence. ${ }^{1}$ Acidosis (especially in children), hypoglycaemia, and hypokalaemia may occur at these concentrations. ${ }^{1}$ High BACs, i.e. 350 to $450 \mathrm{mg} / 100 \mathrm{~mL}$, cause cold clammy skin, hypothermia, hypotension, stupor, coma, dilated pupils, and depressed or absent tendon reflexes. ${ }^{1}$ Severe alcohol intoxication may cause severe hypoglycemia, convulsions, respiratory depression and metabolic acidosis. ${ }^{1}$

The Center for Substance Abuse Treatment (CSAT) of the United States has slightly different categorizations for BACs and alcohol intoxication symptoms. BACs of 20 to $80 \mathrm{mg} / 100 \mathrm{~mL}$ may cause loss of coordination, mood changes, personality alteration, and increased motor activity. At 80 to $200 \mathrm{mg} / 100 \mathrm{~mL}$, ataxia, slurring of speech and cognitive impairment occur. ${ }^{7}$ At 200 to $300 \mathrm{mg} / 100 \mathrm{~mL}$ nausea and vomiting may occur. This, along with sedation, increases patients' risk for aspiration of stomach contents. ${ }^{7}$ At BACs higher than $300 \mathrm{mg} / 100 \mathrm{~mL}$, hypothermia with impairment of consciousness is likely. Comas begin to be seen at levels of 400 to $600 \mathrm{mg} / 100 \mathrm{~mL} .^{7}$ Martindale states the median lethal BAC to be about 400 to $500 \mathrm{mg} / 100 \mathrm{~mL}$; whereas the CSAT reported that in general BACs between 600 and $800 \mathrm{mg} / 100 \mathrm{~mL}$ are fatal. ${ }^{1,7}$

The safety concerns associated with ethanol exposure may even be more significant in vulnerable populations such as infants and children, pregnant women and the elderly. To explain the harmful effects of ethanol in different populations, it is important to first understand the pharmacokinetics of ethanol. Briefly, ethanol undergoes rapid absorption from the gastrointestinal tract. ${ }^{1}$ It is then distributed throughout the body fluids. ${ }^{1}$ About $90-98 \%$ of ethanol metabolism occurs in the liver, where ethanol is converted by alcohol dehydrogenase $(\mathrm{ADH})$ to acetaldehyde through oxidation. ${ }^{1}$ Other metabolism pathways are available, including the hepatic microsomal oxidising system and catalase activity, but the ADH pathway is predominant. ${ }^{1}$ The remaining $2-10 \%$ is excreted unchanged by the kidneys and lungs.

There is limited toxicity data of acute and chronic ethanol exposure in the paediatric population. ADH activity of infants and children has been found to be significantly lower than that of adults and may only increase to adult levels at age 5 years. ${ }^{8,9}$ Since ADH is the rate-limiting enzyme in ethanol metabolism, children younger than 5 years were reported to have reduced ethanol clearance rate, resulting in plasma accumulation of ethanol. ${ }^{9,10}$. However, other studies have found the rate of serum ethanol clearance in acutely intoxicated paediatric patients to be comparable to or even faster than that in adults. ${ }^{10-12}$ This may be attributed to higher catalase activity, an alternative metabolic pathway for ethanol, which may compensate for the reduced $\mathrm{ADH}$ activity. ${ }^{13}$ In a nutshell, current evidence is not sufficiently conclusive to show paediatric patients metabolise ethanol less efficiently than adults. Nevertheless, symptoms of alcohol intoxication may be more severe in children and may occur at a much lower BAC compared to adults. ${ }^{3}$ Lethal BAC may also be lower in children. ${ }^{3}$ Moreover, paediatric groups are more susceptible to severe hypoglycaemia following acute ethanol intoxication. ${ }^{3,14}$

Furthermore, paediatric medications are often formulated as liquid for compliance purposes. This inevitably increases the risk of undesirable ethanol exposure in paediatric patients because liquid formulations often contain higher levels of ethanol. Although many medicines containing ethanol are not licensed in these age groups, off-label uses of these medications are common and may lead to ethanol toxicity in paediatric patients. The long-term effects of low-level ethanol exposure on children's health and growth have not been thoroughly evaluated. The general consensus is that paediatric groups should be protected from the potential harmful effects of ethanol, and that ethanol should not be used in paediatric medications unless the benefit outweighs the risk. If used, ethanol content should be kept to a minimum amount.
Alcohol intake during pregnancy can cause severe harmful effects to the fetus as ethanol crosses the placenta readily. ${ }^{1}$ Fetal alcohol syndrome (FAS), the leading cause of congenital mental retardation, is the result of severe neurodevelopmental impairments due to prenatal alcohol exposure. ${ }^{15}$ Children with FAS commonly suffer from impairment in visuospatial functioning, verbal and nonverbal learning, attention and executive functioning, as well as behavioural problems. ${ }^{16}$

In the elderly, ethanol metabolism is reduced due to the decreased activity of metabolic enzymes such as $\mathrm{ADH}$, acetaldehyde dehydrogenase and cytochrome P450-2E1. ${ }^{17}$ The volume of distribution also decreases with age. ${ }^{17}$ This results in increased blood ethanol level, causing the elderly to be more prone to the adverse effects of ethanol exposure. Furthermore, ethanol can interact with numerous drugs, increasing their plasma concentration and hence leading to toxicity. Polypharmacy is common in elderly patients; hence they have an increased risk of developing drug interaction from ethanol intake.

\section{Standards for alcohol concentration in OTC medication and labelling requirement}

To reduce ethanol exposure and prevent misuse of OTC medicines for their alcohol content, the Food and Drug Administration (FDA) issued guidance on the maximum alcohol concentrations of oral OTC medication for different age groups. For adults and children over 12 years, the maximum alcohol concentration is $10 \%$; for children under 12 and under 6 years old, the maximum alcohol concentrations are $5 \%$ and $0.5 \%$ respectively. ${ }^{18}$

The risk of undesirable ethanol exposure from traditional herbal medicines is even more alarming than that of pharmaceutical preparations. The alcohol content of herbal products undergoes less rigorous regulation, and there is a lack of guidelines relating to safe limits for ethanol. Thus, traditional herbal preparations may contain significant concentrations of ethanol and impose a higher risk of ethanol toxicity than pharmaceutical medicines since herbal products are easily available on the market without a prescription or advice from healthcare professionals. A patient may use traditional herbal medicines for a prolonged period, unnecessarily, and may even take more than one herbal product containing ethanol concurrently. Therefore, traditional herbal products are more likely to cause chronic ethanol exposure. Consequently, it is important to identify the ethanol content in traditional herbal products available on the market, as well as to develop regulation to guide the use of ethanol in these products and ensure ethanol content is disclosed on product packaging.

The European Medicine Agency (EMA) had made some recommendations regarding the use of ethanol-containing herbal medicinal products in paediatric patients. ${ }^{3}$ Highlighted below are several important recommendations:

- All herbal medicinal products containing ethanol should not be used in children under 2 years unless adequately justified.

- Since psychomotor functions impairment may occur at blood ethanol concentrations above $0.125 \mathrm{~g} / \mathrm{L}$, it is recommended that blood ethanol concentration should not exceed $0.125 \mathrm{~g} / \mathrm{L}$ following a single dose of herbal medicinal product.

- The dose interval should be kept as long as possible, at least 4 hours, to avoid accumulation.

- The product should be used for the shortest possible period.

- Other medicinal products containing ethanol should not be used concurrently.

- The ethanol content of the product should be disclosed clearly on the package leaflet.

This study aims to scrutinize the concentration of ethanol in the traditional herbal cough syrups available on the Malaysian market. The 
findings of this study can serve as a basis for strengthening the enforcement of ethanol content regulation in traditional herbal preparations to address ethanol toxicity concerns, as well as for encouraging stricter regulation on labelling requirements and ethanol content disclosure so that consumers and healthcare professionals are able to make informed decision on the most appropriate medicinal treatment.

\section{METHOD}

\section{Study design}

An analytical and quantitative approach was adopted to estimate the alcohol contents of five selected herbal cough syrups. The syrup brands used in this study were chosen due to their popularity among Malaysian consumers, which can be attributed to the marketing efforts via media outlets. These syrups are also easily accessible by the public, as they are commonly sold in local retail stores, supermarkets and community pharmacies.

\section{Materials}

Five traditional herbal cough syrups commercially available in Malaysian market were purchased from a local community pharmacy for use as samples. The ethanol test kit (Roche Yellow Line) was purchased from R-Biopharm AG (Darmstadt, Germany).

\section{Ethanol test kit}

The test kit contains: ${ }^{19}$

1. Bottle 1 with $100 \mathrm{~mL}$ potassium diphosphate buffer solution, which provides a $\mathrm{pH}$ of approximately 9.0 ;

2. Bottle 2 with 30 tablets, each containing $4 \mathrm{mg}$ of nicotinamideadenine dinucleotide (NAD) and $0.8 \mathrm{U}$ of aldehyde dehydrogenase (Al-DH);

3. Bottle 3 with $1.6 \mathrm{~mL}$ suspension consisting of $7000 \mathrm{U} \mathrm{ADH}$;

4. Bottle 4 with ethanol assay control solution for assay control purposes.

\section{Other}

Distilled water was used as a diluent for the preparation of sample syrups, and as the blank for UV spectrophotometry.

\section{Assay method}

Enzymatic analysis was carried out to determine the ethanol content in each syrup sample. The principle reaction utilised is shown below, whereby ethanol is oxidized by NAD in the presence of the enzyme $\mathrm{ADH}$, forming the products acetaldehyde, reduced NAD (NADH) and a proton. ${ }^{19}$

$$
\text { Ethanol }+\mathrm{NAD}^{+} \stackrel{\mathrm{ADH}}{\rightleftharpoons} \text { acetaldehyde }+\mathrm{NADH}+\mathrm{H}^{+}
$$

Since the equilibrium of this reaction lies on the side of ethanol and $\mathrm{NAD}$, it is necessary to displace the equilibrium to the right side so that the reaction proceeds towards forming $\mathrm{NADH}$, the detection product. ${ }^{19}$ To achieve this, the reaction should be carried out in alkaline conditions and the acetaldehyde formed should be trapped by using Al-DH. ${ }^{19}$

$$
\text { Acetaldehyde }+\mathrm{NAD}^{+}+\mathrm{H}_{2} \mathrm{O} \stackrel{\mathrm{Al}-\mathrm{DH}}{\longrightarrow} \text { Acetic acid }+\mathrm{NADH}+\mathrm{H}^{+}
$$

The ethanol content can be quantitatively determined by detecting $\mathrm{NADH}$ using UV spectrophotometry, i.e. measuring its absorbance at a wavelength of $340 \mathrm{~nm}^{19}$

\section{Equipment}

A UV-Vis single-beam spectrophotometer (UV mini-1240, Shimadzu, Japan) with spectrum bandwidth of $5 \mathrm{~nm}$ and wavelength accuracy of $\pm 1.0 \mathrm{~nm}$ was employed to determine the absorbance of the sample solutions. Disposable plastic UV-cuvettes macro $(1.00 \mathrm{~cm}$ light path) were used to hold the sample solutions. Calibrated glassware and scientific equipment were used throughout the whole study.

\section{Standard stock solutions and working solutions}

A standard stock solution for each syrup was prepared by diluting an accurately measured $5 \mathrm{~mL}$ of the syrup in a $100 \mathrm{~mL}$ volumetric flask, making up to the mark using distilled water. This resulted in 20 -fold dilution of the syrup.

Working solutions were prepared by diluting accurately measured $2.5 \mathrm{~mL}$ of each stock solution in a separate $50 \mathrm{~mL}$ volumetric flask, making up to the mark using distilled water. This resulted in a further 20 -fold dilution. Hence, the final dilution factor in each working solution was 400 .

\section{Procedure}

\section{(i) Preparation of test reagents}

The protocol published by R-Biopharm was employed for the preparation of test reagents provided in the ethanol test kit.

Six disposable cuvettes were needed for each replicate of the assay: one cuvette for blank analysis, and five cuvettes for sample analysis (one cuvette for each syrup). One tablet was transferred from Bottle 2 to each cuvette using forceps provided in the test kit. Using a micropipette, $3 \mathrm{~mL}$ of buffer was transferred from Bottle 1 to each cuvette to dissolve the tablet.

\section{(ii) Assay protocol}

The assay procedure used was in accordance with the protocol published by R-Biopharm for the ethanol test kit. Each cuvette from the previous procedure contains dissolved NAD and Al-DH. A blank was set up in the first cuvette by adding $100 \mu \mathrm{L}$ of distilled water to the cuvette. As for sample cuvettes, $100 \mu \mathrm{L}$ of each working sample solution was added to its respective cuvette. Following addition of sample solutions, the contents of the cuvettes were mixed using a micropipette. The cuvettes were then covered with Parafilm to prevent assay mixture from adsorbing ethanol from air. After 3 minutes, the absorbance for all the solutions was read at $340 \mathrm{~nm}$. The absorbance results obtained are denoted as $\mathrm{A}_{1}$.

To start the enzymatic reaction, $50 \mu \mathrm{L}$ of $\mathrm{ADH}$ suspension from Bottle 3 was added to each cuvette. Following each addition, the content of each cuvette was mixed using a micropipette. The cuvettes were then covered with Parafilm. After approximately 5-10 minutes, the reaction was expected to be completed. The absorbance of the solutions was read immediately one after another at $340 \mathrm{~nm}$. These absorbance results are denoted as $\mathrm{A}_{2}$.

Two replicates of the assay were then carried out. The complete procedure is summarised in Table 1, which is adapted from the protocol published by R-Biopharm.

\section{Data analysis}

After obtaining the $A_{1}$ and $A_{2}$ readings for each sample, the measured absorbance difference $(\triangle A)$ was calculated using the following equation: $\Delta \mathrm{A}=\left(\mathrm{A}_{2}-\mathrm{A}_{1}\right)_{\text {sample }}-\left(\mathrm{A}_{2}-\mathrm{A}_{1}\right)_{\text {blank }}$

(N.B. To achieve sufficiently precise results, $\Delta \mathrm{A}$ should be at least 0.100 absorbance units.)

Next, to calculate ethanol concentration $\left(\mathrm{C}_{\mathrm{Ethanol}}\right)$ in each sample, the following equation was used:

$$
\mathrm{C}_{\mathrm{Ethanol}}=\frac{\mathrm{V} \times \mathrm{MW}}{\varepsilon \times \mathrm{d} \times \mathrm{v} \times 2 \times 1000} \times \Delta \mathrm{A} \times \mathrm{F}(\mathrm{g} \text { ethanol/ L sample solution })
$$


Table 1: Procedure summary (adapted from "UV-method for the determination of ethanol in foodstuffs and other materials", R-Biopharm)

\begin{tabular}{|c|c|c|}
\hline Pipette into cuvettes & Blank & Sample \\
\hline Solution (Bottle 1) & $3.000 \mathrm{~mL}$ & $3.000 \mathrm{~mL}$ \\
\hline Tablet (Bottle 2) & 1 & 1 \\
\hline Distilled water & $0.100 \mathrm{~mL}$ & - \\
\hline Working sample solution & - & $0.100 \mathrm{~mL}$ \\
\hline \multicolumn{3}{|c|}{$\begin{array}{l}\text { Mix. After approx. } 3 \text { min read absorbances of the solutions }\left(A_{1}\right) \text {. Start reaction } \\
\text { by addition of: }\end{array}$} \\
\hline Suspension (Bottle 3) & $0.050 \mathrm{~mL}$ & $0.050 \mathrm{~mL}$ \\
\hline
\end{tabular}

$\mathrm{V}=$ final volume $(\mathrm{mL}) ; \mathrm{MW}=$ molecular weight of ethanol; $\varepsilon=$ extinction coefficient of $\mathrm{NADH}$ at $340 \mathrm{~nm}\left(\mathrm{~L} \mathrm{x} \mathrm{mmol}^{-1} \mathrm{x} \mathrm{cm}^{-1}\right)$; $\mathrm{d}=$ light path $(\mathrm{cm})$; $\mathrm{v}=$ sample volume $(\mathrm{mL}) ; \Delta \mathrm{A}=$ measured absorbance difference;

$\mathrm{F}=$ dilution factor

Hence, a simplified equation was obtained by substituting values into the previous equation:

$$
\mathrm{C}_{\text {Ethanol }}=\frac{3.150 \times 46.07}{6.3 \times 1.00 \times 0.100 \times 2 \times 1000} \times \Delta \mathrm{A} \times 400
$$

$\mathrm{C}_{\text {Ethanol }}=46.07 \mathrm{x} \Delta \mathrm{A}$ (g ethanol/ L sample solution)

$\mathrm{C}_{\text {Ethanol }}(\mathrm{g} / \mathrm{L})$ values of the samples were converted into percentage ethanol by volume $(\% \mathrm{v} / \mathrm{v})$ using the following equation:

$$
\begin{aligned}
\text { Percentage }_{\text {Ethanol }}= & \frac{\text { Ethanol concentration }(\mathrm{g} / \mathrm{L})}{10 \times \text { density }(\mathrm{g} / \mathrm{mL})} \\
& =\frac{\text { Ethanol concentration }(\mathrm{g} / \mathrm{L})}{10 \times 0.78924(\mathrm{~g} / \mathrm{mL})}
\end{aligned}
$$$$
\text { Percentage }_{\text {Ethanol }}=\mathrm{C}_{\text {Ethanol }} / 7.8924(\% \mathrm{v} / \mathrm{v})
$$

\section{RESULTS}

\section{Raw absorbance data}

To achieve the objective of this study, five traditional cough syrups were selected as test samples, and alcohol determination protocol was implemented. Upon quantitative assessment using UV-Vis spectrophotometer readings at $340 \mathrm{~nm}$, baseline absorbance $\left(\mathrm{A}_{1}\right)$ and final absorbance $\left(\mathrm{A}_{2}\right)$ of the blank and samples obtained after adding the test reagents are shown in Table 2.

\section{Ethanol concentration quantification}

Calculation steps were performed as described in the "Data analysis" section under "Method". All calculated results, as well as the average percentage ethanol by volume $(\% \mathrm{v} / \mathrm{v})$ for each syrup obtained from the triplicate assays, are shown in Table 3. Upon final calculation, the average $\% \mathrm{v} / \mathrm{v}$ ethanol in the tested syrups range from $0.102 \%$ to $2.576 \%$.

\section{DISCUSSION}

\section{Compliance of syrup alcohol content with guidelines}

Among all tested syrups, S1 was found to contain the lowest amount of ethanol, i.e. $0.102 \%$, followed by S2 with $0.154 \%$. S4 was found to contain $1.07 \%$ of ethanol and S5 $2.091 \%$. S3 contains the highest amount of ethanol, namely $2.576 \%$.

According to FDA guidance, the alcohol concentration limit of oral OTC medication is $10 \%$ for adults and children above 12 years, $5 \%$ for children aged $6-12$, and $0.5 \%$ for children under 6 years. ${ }^{18}$ All studied samples comply with the FDA requirement for use in adults and children above 6 years since they do not contain more than $5 \%$ ethanol.

However, S3, S4 and S5 do not fulfil the requirement for use in children under 6 years as they contain higher than $0.5 \%$ ethanol. Yet, these three syrups are inappropriately indicated for use in children older than 3 years as stated on their packaging.

\section{Safety analysis}

The amount of ethanol ingested per dose for each syrup was calculated by multiplying the average $\mathrm{C}_{\mathrm{Ethanol}}$ by the volume of a single dose stated on the product packaging. Then, the maximum daily ethanol exposure attributed to the syrup intake was calculated by multiplying ingested ethanol per dose by the dose frequency as indicated on the product packaging. Lastly, the blood alcohol concentration (BAC) following a single dose was calculated using the equation below: ${ }^{2}$

$$
\text { Blood Alcohol Concentration }(\mathrm{g} / \mathrm{L})=\frac{\begin{array}{c}
\text { Ingested ethanol in a } \\
\text { single dose }(\mathrm{g})
\end{array}}{\begin{array}{l}
\text { Volume of distribution }(\mathrm{L} / \mathrm{kg}) \times \\
\text { Weight }(\mathrm{kg})
\end{array}}
$$

The volume of distribution is assumed to be $0.6 \mathrm{~L} / \mathrm{kg}$. For adults, the average weight of $60 \mathrm{~kg}$ is used for calculation. For children, the average weight for a 6 year old i.e. $20 \mathrm{~kg}$ is used. All results are presented in Table 4 . According to the recommendation of the EMA, BAC should not exceed $0.125 \mathrm{~g} / \mathrm{L}$ following a single dose of herbal medicinal product to avoid psychomotor function impairment. ${ }^{3}$ The results show that all studied syrups will not induce a BAC higher than $0.125 \mathrm{~g} / \mathrm{L}$ after a single dose, provided that the volume of syrup taken does not exceed the recommended dose. Hence, the ethanol

Table 2: UV absorbance readings

\begin{tabular}{ccccccc}
\hline \multirow{2}{*}{ Sample } & \multicolumn{2}{c}{ 1st run } & \multicolumn{2}{c}{ 2nd run } & \multicolumn{2}{c}{ 3rd run } \\
\cline { 2 - 7 } & $\mathrm{A}_{1}$ & $\mathrm{~A}_{2}$ & $\mathrm{~A}_{1}$ & $\mathrm{~A}_{2}$ & $\mathrm{~A}_{1}$ & $\mathrm{~A}_{2}$ \\
\hline Blank & 0.244 & 0.298 & 0.269 & 0.290 & 0.253 & 0.288 \\
S1 & 0.291 & 0.342 & 0.279 & 0.327 & 0.257 & 0.300 \\
S2 & 0.280 & 0.341 & 0.304 & 0.350 & 0.284 & 0.366 \\
S3 & 0.270 & 0.692 & 0.283 & 0.758 & 0.303 & 0.840 \\
S4 & 0.253 & 0.512 & 0.272 & 0.441 & 0.284 & 0.516 \\
S5 & 0.294 & 0.677 & 0.260 & 0.650 & 0.264 & 0.676 \\
\hline
\end{tabular}


Table 3: Measured absorbance difference $(\Delta A)$, ethanol concentration $\left(C_{E \text { thanol }}\right)$ and percentage ethanol by volume $(\% \mathrm{v} / \mathrm{v}$ ethanol) calculated for each syrup.

\begin{tabular}{|c|c|c|c|c|c|c|c|c|c|c|}
\hline \multirow{2}{*}{ Syrup } & \multicolumn{3}{|c|}{ 1st run } & \multicolumn{3}{|c|}{2 nd run } & \multicolumn{3}{|c|}{$3 r d$ run } & \multirow{2}{*}{$\begin{array}{c}\text { Average } \% v / v \\
\text { ethanol }\end{array}$} \\
\hline & $\Delta \mathrm{A}$ & $C_{\text {Ethanol }}(g / L)$ & $\begin{array}{c}\% \mathrm{v} / \mathrm{v} \\
\text { ethanol }\end{array}$ & $\Delta \mathrm{A}$ & $C_{\text {Ethanol }}(g / L)$ & $\begin{array}{c}\% v / v \\
\text { ethanol }\end{array}$ & $\Delta \mathrm{A}$ & $C_{\text {Ethanol }}(g / L)$ & $\begin{array}{c}\% v / v \\
\text { ethanol }\end{array}$ & \\
\hline $\mathrm{S}^{*}$ & $-3 \times 10^{-3}$ & $-* *$ & $-* *$ & 0.027 & 1.244 & 0.158 & $8 \times 10^{-3}$ & 0.369 & 0.0467 & $0.102 \%$ \\
\hline $\mathrm{S} 2^{*}$ & $7 \times 10^{-3}$ & 0.323 & 0.041 & 0.025 & 1.152 & 0.146 & 0.047 & 2.165 & 0.274 & $0.154 \%$ \\
\hline S3 & 0.368 & 16.954 & 2.148 & 0.454 & 20.916 & 2.650 & 0.502 & 23.127 & 2.930 & $2.576 \%$ \\
\hline S4 & 0.205 & 9.444 & 1.197 & 0.148 & 6.818 & 0.864 & 0.197 & 9.076 & 1.150 & $1.070 \%$ \\
\hline S5 & 0.329 & 15.157 & 1.920 & 0.369 & 17.000 & 2.154 & 0.377 & 17.368 & 2.200 & $2.091 \%$ \\
\hline
\end{tabular}

* S1 and S2: Results are not sufficiently precise because $\Delta \mathrm{A}<0.1$ units

${ }^{*}$ S1 (1st run): Unable to calculate due to negative $\Delta \mathrm{A}$ value.

Table 4: Ethanol ingested per dose, maximum daily ethanol exposure and blood ethanol concentration following a single dose calculated for each syrup

\begin{tabular}{|c|c|c|c|c|c|c|}
\hline \multirow[t]{2}{*}{ Syrup } & \multicolumn{2}{|c|}{ Ethanol ingested per dose (mg) } & \multicolumn{2}{|c|}{ Maximum daily exposure (mg) } & \multicolumn{2}{|c|}{$\begin{array}{l}\text { Blood Alcohol Concentration after single dose } \\
\qquad(\mathrm{g} / \mathrm{L})\end{array}$} \\
\hline & Adult & Child* & Adult & Child* & Adult & Child (6 yrs) \\
\hline \multirow[t]{2}{*}{ S1 } & 8.06 & $2-12$ years: 4.03 & 24.18 & $2-12$ years: 12.09 & 0.000224 & 0.000336 \\
\hline & & $6-12$ years: $6.066-12.13$ & & $6-12$ years: 48.53 & & \\
\hline \multirow[t]{2}{*}{ S2 } & 24.26 & 3-5 years: & 97.04 & 3-5 years: & 0.000674 & 0.00101 \\
\hline & & $3.033-6.066$ & & 24.26 & & \\
\hline S3 & 203.32 & $\begin{array}{c}\text { 3-12 years: } \\
101.66\end{array}$ & 609.96 & $\begin{array}{c}\text { 3-12 years: } \\
304.98\end{array}$ & 0.00565 & 0.00847 \\
\hline \multirow{4}{*}{ S4 } & \multirow{4}{*}{42.23} & 7-12 years: & \multirow{4}{*}{126.69} & 7-12 years: & \multirow{4}{*}{0.00117} & \multirow{4}{*}{0.00232} \\
\hline & & 27.87 & & 83.62 & & \\
\hline & & 2-6 years: & & 2-6 years: & & \\
\hline & & 14.36 & & 43.08 & & \\
\hline \multirow{4}{*}{ S5 } & \multirow{4}{*}{165.08} & $6-12$ years: & \multirow{4}{*}{660.32} & $6-12$ years: & \multirow{4}{*}{0.00459} & \multirow{4}{*}{0.00688} \\
\hline & & 82.54 & & 82.54 & & \\
\hline & & 2-6 years: & & 2-6 years: & & \\
\hline & & 41.27 & & 41.27 & & \\
\hline
\end{tabular}

*The age groups shown in the child columns for ingested ethanol per dose and maximum daily exposure are according to the indicated age groups of each syrup as stated on the product packaging. Calculations were performed using the volume of single dose and dose frequency indicated for each age group as stated on the product packaging of each syrup.

content for all studied syrups can be deemed safe and appropriate by EMA's standard.

\section{Compliance of labelling with Malaysian guidelines}

On the other hand, none of these syrups comply with Malaysian Drug Registration Guidance on labelling requirements as they do not disclose their alcohol contents on the packagings and information leaflets. According to the Drug Registration Guidance Document published by the National Pharmaceutical Regulatory Agency, all medicinal entities including OTC and traditional products should include alcohol content on the labelling of unit carton and package insert. ${ }^{20}$

Despite having a safe alcohol level, the disclosure of alcohol content is still important for patients' rights and safety. The consumers as well as healthcare professionals need to be alerted to the presence of alcohol in these products so that they can make fully informed decisions about product selection. Undisclosed ethanol content may increase chances of consumers taking several alcohol-containing products concomitantly, be it medicinal syrup or other beverages, which may in turn lead to toxic alcohol blood levels. Consumers may also get undesirable chronic alcohol exposure if they take the products in question for a long time without knowing the alcohol content. Therefore, more rigorous regulation on alcohol content in herbal preparation, and disclosure of alcohol content in packaging, should be enforced.

\section{CONCLUSION}

Although all studied syrups contain a safe level of ethanol in accordance with the EMA recommendation as well as the FDA requirement for use in adults and children above 6 years, none of them comply with Malaysia Drug Registration Guidance on labelling requirements as they do not disclose their alcohol content on their unit carton and package insert. Three out of five studied syrups do not fulfil the FDA requirement for use in children less than 6 years, yet they are inappropriately indicated on their packaging for use in children older than 3 years. Non-compliance with labelling requirements, inappropriate age indication of traditional herbal medicinal syrups, and the fact that these products are easily accessible without prescription put consumers at risk of both acute and 
chronic alcohol toxicity. These findings strengthen the need for stricter enforcement of ethanol-content disclosure and appropriate labelling.

\section{ACKNOWLEDGEMENT}

Authors are grateful to Halal Ecosystem (HE) Multidisciplinary Platform, Monash University Malaysia for project funding.

\section{CONFLICT OF INTEREST}

The authors declare to have no conflict of interest associated with this work.

\section{ABBREVIATION USED}

ADH: Alcohol dehydrogenase; Al-DH: Aldehyde dehydrogenase; BAC: Blood alcohol concentration; CNS: Central nervous system; CSAT: Center for Substance Abuse Treatment; EMA: European Medicine Agency; FAS: Fetal alcohol syndrome; FDA: Food and Drug Administration; NAD: Nicotinamide-adenine dinucleotide; NADH: Reduced NAD; OTC: Over-the-counter.

\section{REFERENCES}

1. Alcohol, Drug Monographs, Martindale.

2. Committee for Human Medicinal Products. Questions and Answers on Ethano in the context of the revision of the guideline on 'Excipients in the label and package leaflet of medicinal products for human use' (CPMP/463/00). London: European Medicines Agency; 2014.

3. European Medicines Agency. Committee on Herbal Medicinal Products Reflection paper on ethanol content in herbal medicinal products and traditional herbal medicinal products used in children (EMA/HMPC/85114/2008). London: European Medicines Agency; 2014.

4. Strickley RG. Solubilizing excipients in oral and injectable formulations. Pharmaceutical research. 2004;21(2):201-30

5. American Academy of Pediatrics, Committee on Drugs 'Ethanol in liquid preparations intended for children', Pediatrics 1984;73(3):405-7

6. Fiocchi A, Riva E, Giovannini M. Ethanol in medicines and other products intended for children: commentary on a medical paradox. Nutrition Research 1999;19(3):373-9

7. Center for Substance Abuse Treatment. Detoxification and Substance Abuse Treatment. Treatment Improvement Protocol (TIP) Series 45. DHHS Publication No. (SMA) 06-4131. Rockville, MD: Substance Abuse and Mental Health Services Administration, 2006.

8. Pikkarainen PH, Räihä NC. Development of alcohol dehydrogenase activity in the human liver. Pediatric Research. 1967;1(3):165-8

9. Strolin Benedetti M, Whomsley R, Baltes E. Differences in absorption, distribution, metabolism and excretion of xenobiotics between the paediatric and adult populations. Expert Opinion on Drug Metabolism \& Toxicology. 2005;1(3):447-71.

10. Zuccotti G, Fabiano V. Safety issues with ethanol as an excipient in drugs intended for pediatric use. Expert Opinion on Drug Safety. 2011;10(4):499-02.

11. Simon H, Cox J, Sucov A, Linakis J. Serum Ethanol Clearance in Intoxicated Children and Adolescents Presenting to the ED. Academic Emergency Medicine. 2008; 1(6):520-4

12. Ragan F. Ethanol ingestion in children. A five-year review. JAMA: The Journal of the American Medical Association. 1979; 242(25):2787-88

13. Tran M, Wu A, Hill D. Alcohol dehydrogenase and catalase content in perinatal infant and adult livers: Potential influence on neonatal alcohol metabolism Toxicology Letters. 2007;169(3):245-52.

14. Marek E, Kraft W. Ethanol Pharmacokinetics in Neonates and Infants. Current Therapeutic Research. 2014; 76:90-7.

15. Spohr HL, Willms J, Steinhausen HC. Prenatal alcohol exposure and long-term developmental consequences. The Lancet. 1993;341(8850):907-10.

16. Riley E, McGee C. Fetal Alcohol Spectrum Disorders: An Overview with Emphasis on Changes in Brain and Behavior. Experimental Biology and Medicine. 2005;230(6):357-65

17. Meier, P. and Seitz H., Age, Alcohol metabolism and liver disease. Curr Opin Clin Nutr Metab Care, 2008. 11(1):p.21-6

18. Food and Drug Administration. Part 328- Over the counter drug products intended for oral ingestion that contain ethanol. Title 21- Food and Drugs. Rockville, MD: Department of Health and Human Services (US), Food and Drug Administration; 006.

19. R-Biopharm AG. Ethanol UV-method for the determination of ethanol in foodstuffs and other materials. Darmstadt: R-Biopharm;2014

20. National Pharmaceutical Regulatory Agency. Drug Registration Guidance Document. Petaling Jaya: National Pharmaceutical Regulatory Agency, Ministry of Health Malaysia;2016.

\section{GRAPHICAL ABSTRACT}

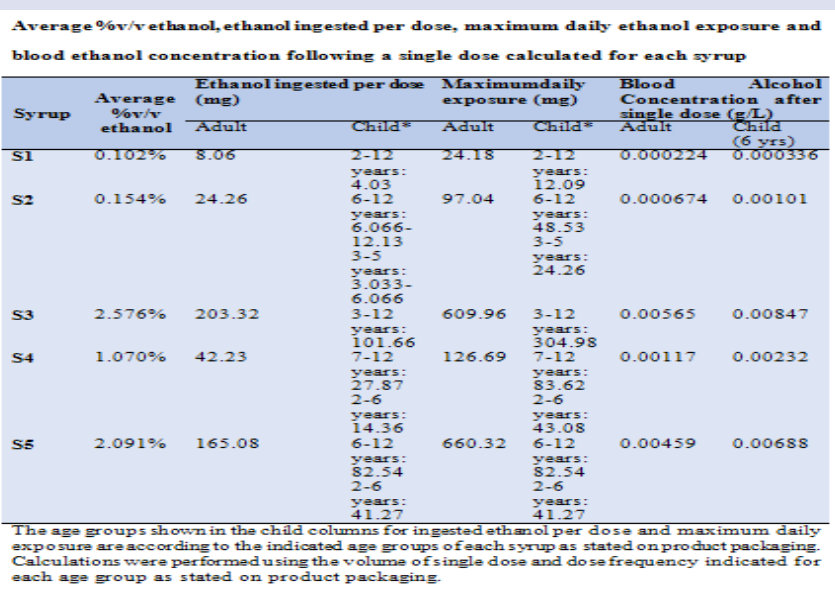

\section{SUMMARY}

- The use of alcohol as an excipient in pharmaceutical preparations raises safety concerns, especially when used in high concentration. This study aims to scrutinize the ethanol concentration in traditional herbal cough syrups available overthe-counter (OTC) in Malaysia. Enzymatic analysis was adopted to estimate the alcohol contents of five selected syrups. The principle reaction involved ethanol oxidation by nicotinamide-adenine dinucleotide (NAD) in the presence of the enzyme alcohol dehydrogenase $(A D H)$, forming acetaldehyde, reduced $N A D$ (NADH) and a proton. The ethanol concentration of each syrup was quantitatively determined by detecting NADH using UV spectrophotometry at detection wavelength of $340 \mathrm{~nm}$. The ethanol percentage by volume (\% v/v) in the tested syrups ranges from $0.102 \%$ to $2.576 \%$. All five syrups studied comply with the FDA requirement for drugs for adults and children $>6$ years since they do not contain more than $5 \%$ ethanol. However, three syrups do not fulfil the requirement for use in children $<6$ years as they contain higher than $0.5 \%$ ethanol, yet they are inappropriately indicated on their packaging for use in children 3 years. In terms of safety, all studied syrups fulfil European Medicine Agency's (EMA) recommendation as they will not induce a blood alcohol concentration (BAC) higher than $0.125 \mathrm{~g} / \mathrm{L}$ after a single dose. Nevertheless, none of these syrups comply with Malaysian Drug Registration Guidance on labelling requirements as they do not disclose their alcohol contents on the packaging.More rigorous regulation on alcohol content in herbal preparations, and disclosure of alcohol content in product packagings should be enforced. 


\section{ABOUT AUTHORS}

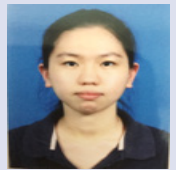

Ming Shin Neo completed Bachelor of Pharmacy from Monash University, Malaysia. Her research interest is in the safety and efficacy of OTC medications.

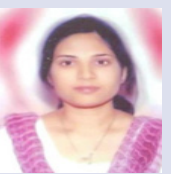

Shraddha Manish Gupta graduated in Pharmaceutical sciences from Pune University, (NDMVP's College of Pharmacy, Nashik, India) in 2003.She received her M.Pharm (Master of Pharmacy) degree from Pune University, (NDMVP's College of Pharmacy, Nasik, India) in 2006. She had a teaching experience of many years. She had a research interest in computational chemistry.

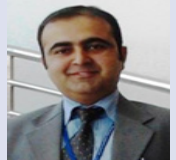

Dr. Tahir Mehmood Khan is stream leader in clinical pharmacy at school of Pharmacy, Monash University, Malaysia. His prime interest is in clinical pharmacy and evidence synthesis. He is also focusing on "Halal medicines" and implementation of Halal standards in the pharmaceutical preparations. In addition, he is also associate member of "Halal Eco System Platform", Monash University, Malaysia. He has more than 200 peer review articles.

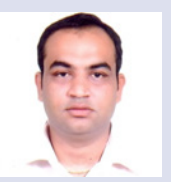

Dr. Manish Gupta graduated in Pharmaceutical sciences from College of Pharmacy, IPS Academy, and Indore, India in 2003. He received his M. Pharm (Master of Pharmacy) degree from Dr. Hari Singh Gour University, Sagar, India in 2006. After completion of his M. Pharm he went as an EaStCHEM fellow to pursue PhD in University of Edinburgh, UK. In 2012 he moved to School of Pharmacy, The University of Nottingham, Malaysia as a Postdoctoral Research Scientist on "Biodesign Project" which is funded by the European Commission (EU FP7). Currently he is working as Lecturer in Monash University, Malaysia. He is lead researcher in area of Nano and Micro drug delivery.

Cite this article: Neo MS, Gupta SM, Khan TM, Gupta M. Quantification of Ethanol Content in Traditional Herbal Cough Syrups. Pharmacog J. 2017;9(6):821-7. 